\title{
Analisis Kelayakan Pengembangan Produk Alat Permainan Edukatif dengan Pengenalan Bahasa Arab bagi Anak Usia Dini
}

\author{
H. Ekie Gilang Permata ${ }^{1}$, Annisha Laila ${ }^{2}$ \\ 1,2) Program Studi Teknik Industri, Fakultas Sains dan Teknologi, \\ Universitas Islam Negri Sultan Syarief Kasim Riau \\ Jl. Subrantas Km. 15, Pekanbaru, 28293, Indonesia \\ Email: ekiegp@yahoo.com ${ }^{1} \underline{\text { anisalaila44@gmail.com }}^{2}$
}

\begin{abstract}
The Educational Game Tool is a game tool that intentionally designed specifically for educational purposes. In the industrial world, doing business in the world of toys is a very prospect and opportunity. Feasibility studies need to be carried out to avoid risk of loss, facilitate planning, facilitate the implementation of work, facilitate supervision and facilitate control. Consideration is carried out on the technical, financial and market aspects and marketing aspects to see whether these children's toys are feasible or not to be produced and marketed. The purpose of the study was to determine the level of feasibility of developing educational game products by introducing Arabic to early childhood in terms of technical, financial, market and marketing aspects. From the results of the study obtained the level of agreement on the market and marketing aspects of the 15 statements given were above $90.29 \%$ which means the statements given by each respondent, the respondents agreed. In technical aspect, it is known that balsa wood has a lead time of one week, so the company must do planning and scheduling orders to do safety stock. In the financial aspects, the initial investment needs of Rp. 166,536,000.00, the NPV has a positive value of Rp. $824,715,456.00$ with an interest rate of $8 \%$, the IRR is $67 \%$ greater than MAAR $8 \%$ and PP is obtained for 1 year 7 months 6 days.
\end{abstract}

Keywords: Industry Feasibility Analysis, Market Aspects and Marketing, Technical Aspects, Financial Aspects

\begin{abstract}
Abstrak
Alat Permainan Edukatif (APE) adalah alat permainan yang sengaja dirancang secara khusus untuk kepentingan pendidikan. Dalam dunia industri, berbisnis dalam dunia mainan memiliki prospek dan peluang yang sangat baik. Studi kelayakan dilakukan untuk menghindari risiko kerugian, memudahkan perencanaan, dan pelaksanaan pekerjaan, juga memudahkan pengawasan serta pengendalian. Pertimbangan dilakukan pada aspek teknis, aspek finansial dan aspek pasar dan pemasaran untuk melihat apakah produk mainan anak ini layak atau tidak untuk di produksi dan dipasarkan. Tujuan penelitian ialah untuk mengetahui tingkat kelayakan pengembangan produk alat permainan edukatif dengan pengenalan bahasa arab bagi anak usia dini ditinjau dari aspek teknis, aspek finansial, aspek pasar dan pemasaran. Dari hasil penelitian diperoleh tingkat persetujuan pada aspek pasar dan pemasaran terhadap 15 pernyataan yang diberikan berada diatas 90,29\% yang berarti pernyataan-pernyataan yang diberikan setiap responden, responden menyetujuinya. Pada sapek teknis diketahui bahwa kayu balsa memiliki leadtime selama satu minggu, maka perusahaan harus melakukan perencanaan dan penjadwalan pemesanan untuk melakukan safety stock. Pada aspek keuangan diperoleh kebutuhan investasi awal sebesar Rp. 166.536.000,00, NPV bernilai positif yaitu Rp 824.715.456,00 dengan tingkat suku bunga 8\%, IRR 67\% lebih besar dari MAAR 8\% dan PP diperoleh selama 1 tahun 7 bulan 6 hari.
\end{abstract}

Kata Kunci: Analisis Kelayakan Industri, Aspek Pasar dan Pemasaran, Aspek Teknis, Aspek Finansial 


\section{Pendahuluan}

Perkembangan teknologi semakin pesat dari hari ke hari. Di Indonesia, perkembangan gadget pun cukup pesat. Peminat gadget di Indonesia semakin bertambah dan hampir semua kalangan masyarakat gemar menggunakan gadget. Berikut tabel dari data BPS yang diperbarui per tanggal 21 May 2018, menunjukkan bahwa Riau mengalami peningkatan proporsi individu yang menggunakan telepon genggam sebesar $0,88 \%$.

Tabel 1. Proporsi Penggunakan Telepon Genggam

\begin{tabular}{|c|c|c|}
\hline \multirow[t]{2}{*}{ Provinsi } & \multicolumn{2}{|c|}{$\begin{array}{l}\text { Proporsi Individu Yang } \\
\text { Menggunakan Telepon Genggam } \\
\text { (Persen) }\end{array}$} \\
\hline & 2015 & 2016 \\
\hline $\mathrm{ACEH}$ & 51.50 & 52.97 \\
\hline SUMATERA UTARA & 52.87 & 54.28 \\
\hline SUMATERA BARAT & 57.04 & 57.94 \\
\hline RIAU & 62.10 & 62.98 \\
\hline
\end{tabular}

(Sumber : www.bps.go.id, 2019)
Sekarang tidak hanya orang dewasa saja yang dapat menggunakan gadget. Namun anak-anak juga sudah dapat memilikinya. Oleh karena itu, ada beberapa cara yang harus dilakukan orang tua untuk mencegah dampak negatif dari gadget terjadi pada anak mereka.

Salah satu caranya ialah dengan memberikan anak alat permainan yang edukatif sebagai media pembelajaran dan permainan tersebut berbentuk fisik agar anak tidak selalu menggunakan gadget nya. Alat Permainan Edukatif (APE) adalah alat permainan yang sengaja dirancang secara khusus untuk kepentingan pendidikan. Indonesia sebagai negara dengan mayoritas umat islam, para orang tua seharusnya sudah memberikan edukasi nilai-nilai islami sejak dini. Salah satu yang dapat dilakukan oleh orang tua yaitu dengan memberikan anak alat permainan edukatif islami untuk perkembangan anak dan mengenalkan anak-anak dengan bahasa arab.

Berikut tabel 1. Hasil pernyataan kuesioner terhadap responden.

Tabel 2. Hasil Pernyataan Kuesioner Terhadap Responden

\begin{tabular}{|l|l|r|r|r|r|}
\hline \multirow{2}{*}{ No } & \multicolumn{1}{|c|}{ Pertanyaan } & \multicolumn{4}{|c|}{ Jawaban } \\
\cline { 3 - 6 } 1. & \multicolumn{1}{|c|}{$\begin{array}{l}\text { Ya } \\
\text { gadgah anak sudah bisa menggunakan }\end{array}$} & 30 & $100 \%$ & 0 & $0 \%$ \\
\hline 2. & Apakah anak setiap hari bermain gadget ? & 28 & $93,3 \%$ & 2 & $6,7 \%$ \\
\hline 3. & Apakah anak mempunyai permainan fisik? & 19 & $63,3 \%$ & 6 & $36,7 \%$ \\
\hline 4. & $\begin{array}{l}\text { Apakah anak mempunyai alat permainan } \\
\text { edukatif? }\end{array}$ & 16 & $53,3 \%$ & 5 & $46,7 \%$ \\
\hline 5. & $\begin{array}{l}\text { Apakah anak sudah mengenal huruf-huruf } \\
\text { hijaiyah? }\end{array}$ & 11 & $36,7 \%$ & 10 & $63,3 \%$ \\
\hline 6. & $\begin{array}{l}\text { Apakah anak sudah mengenal bahasa } \\
\text { arab? }\end{array}$ & 11 & $36,7 \%$ & 10 & $63,3 \%$ \\
\hline 7. & $\begin{array}{l}\text { Apakah bapak/ibu tertarik dengan alat } \\
\text { permainan edukatif islami? }\end{array}$ & 30 & $100 \%$ & 0 & $0 \%$ \\
\hline
\end{tabular}

(Sumber: Pengumpulan Data, 2018)

Pada tabel 2. diatas terdapat 7 butir pertanyaan yang disebarkan kepada 30 orang responden. Responden pada kuesioner tersebut ialah orang tua muslim yang memiliki anak dengan rentang usia dari 4 hingga 7 tahun. Dari 30 responden seluruhnya menyatakan bahwa anak sudah bisa menggunakan gadget dan hampir semua anak setiap hari bermain dengan gadgetnya. Hanya $63,3 \%$ anak yang mempunyai permainan fisik. Padahal permainan berbentuk fisik dapat menjauhkan anak dari ketergantungan terhadap penggunaan gadgetnya. Dari hasil kuesioner, 30 orang tua anak tertarik untuk memberikan anak alat permainan edukatif islami agar anak dapat mengenal Bahasa Arab sejak usia dini.

Permainan yang dirancang yaitu berbentuk permainan fisik. Pemilihan bentuk permainan fisik berfungsi agar anak tidak ketergantungan terhadap gadget dan membuat anak lebih sering bersosialisasi dengan teman-teman lainnya . Permainan dibuat berbentuk kosakata Bahasa Arab ataupun potongan ayat-ayat dalam alQur'an. Kosakata tersebut akan dipecah menjadi beberapa potongan ataupun suku 
kata, dan anak dapat menyusunnya sesuai dengan susunan yang tepat. Maka dari itu pemilihan perancangan mainan bongkar pasang dirasa tepat untuk anak usia dini. Berikut gambar produk puzzle huruf hijaiyah.

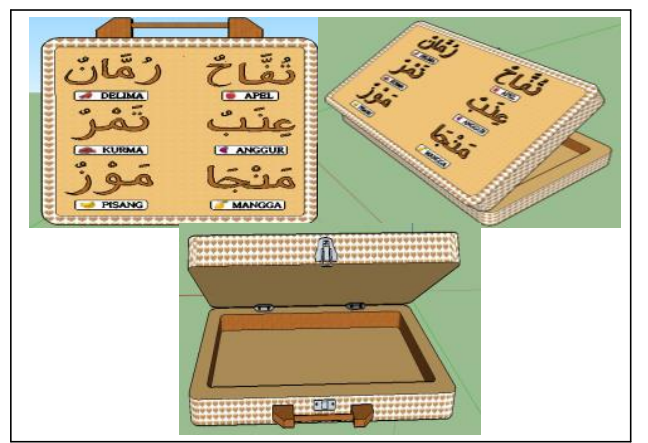

Gambar 1. Produk Puzzle Huruf Hijaiyah

Berdasarkan permasalahan di atas, maka studi kelayakan perlu dilakukan untuk menghindari resiko kerugian, memudahkan perencanaan, memudahkan pelaksanaan pekerjaan, memudahkan pengawasan dan memudahkan pengendalian. Pertimbangan dilakukan pada aspek teknis, aspek finansial dan aspek pasar dan pemasaran untuk melihat apakah poduk mainan anak ini layak atau tidak untuk di produksi dan dipasarkan.

Penelitian yang akan dilakukan bertujuan untuk mengetahui tingkat kelayakan pengembangan produk alat permainan edukatif dengan pengenalan bahasa arab bagi anak usia dini ditinjau dari aspek teknis, aspek finansial, aspek pasar dan pemasaran.

\section{Studi kelayakan bisnis}

Studi kelayakan bisnis adalah suatu kajian ilmu yang menilai pengerjaan suatu bisnis untuk dilihat layak atau tidak layak (feasible or infeasible) dilaksanakan dengan menempatkan ukuran-ukuran baik secara kualitatif dan kuantitatif yang akhirnya terangkum dalam sebuah rekomendasi. Bisnis memang tidak bisa diputuskan tanpa perhitungan mendetail, karena tanpa perhitungan mendetail artinya menyiapkan bisnis untuk masuk dalam default (gagal) (Fahmi, 2014).

Studi kelayakan bisnis merupakan penelitian yang bertujuan untuk memutuskan apakah sebuah ide bisnis layak untuk dilaksanakan atau tidak. Sebuah ide bisnis dinyatakan layak untuk dilaksanakan jika ide tersbut dapat mendatangkan manfaat yang lebih besar bagi semua pihak (stake holder) dibandingkan dampak negatif yang ditimbulkan.

Studi kelayakan bisnis dilakukan untuk mengidentifikasikan masalah dimasa yang akan datang, sehingga dapat meminimalkan kemungkinan melesetnya hasil yang ingin dicapai dalam suatu investasi. Dengan kata lain, studi kelayakan bisnis akan memperhitungkan hal-hal yang akan menghambat atau peluang dari investasi yang akan dijalankan. Jadi dengan adanya studi kelayakan bisnis minimal dapat memberikan pedoman atau arahan kepada usaha yang akan dijalankan nantinya (Kasmir dan Jakfar, 2012).

\section{Aspek-aspek studi kelayakan}

Untuk memperoleh kesimpulan yang kuat tentang dijalankan atau tidaknya sebuah ide bisnis, studi kelayakan bisnis yang mendalam perlu dilakukan pada bebera aspek kelayakan bisnis (Handayani,2016).

\section{Aspek pasar dan pemasaran}

Aspek pasar menempati kedudukan utama dalam penelitian karena perhubungan dengan perebutan pembeli potensial dengan perusahaan lain. Aspek pasar bertujuan antara lain untuk mengetahui ukuran luasnya pasar, pertumbuhan permintaan, kondisi persaingan, siklus hidup produk dan market share dari produk yang bersangkutan. Karakteristik kelayakan aspek pasar adalah adanya demand dan supply terhadap produk atau jasa yang akan ditawarkan, kemudian adanya strategi untuk memasarkan produk dan jasa tersebut (Fahmi, 2014).

\section{Aspek teknis}

Kajian aspek teknis dan produksi mulai dilakukan setelah aspek pasar dan pemasaran dilakukan dan dinyatakan bahwa bisnis tersebut layak dari segi pemasaran. Aspek teknis menjelaskan mesin dan peralatan yang digunakan untuk proses produksi, penyediaan bahan baku dan bagaimana proses produksi dilakukan (Osunbor, 2017).

\section{Aspek finansial}

Dalam analisis finansial dilakukan perhitungan dengan tujuan untuk mengetahui sejauh mana gagasan usaha yang direncanakan dapat memberikan 
manfaat (benefit). Hasil perhitungan analisis finansial merupakan indikator dari modal yang diinvestasikan, yaitu perbandingan antara total benefit yang diterima dengan total biaya yang dikeluarkan dalam bentuk present value selama umur ekonomi proyek. Beberapa hal yang akan dianalisis pada aspek finansial yaitu: analisis investasi, income statement (laporan keuangan), cashflow (arus kas) dan metode evaluasi investasi (payback periode, net present value dan internal rate of return) (Aditya, 2014).

\section{Penentuan Sampel}

Pada penelitian ini sampel yang menjadi objek penelitian adalah para orangtua anak usia dini yang memiliki kecenderungan bermain gadget dan baru mulai mengenalkan bahasa arab kepada anaknya. Pada penelitian ini jumlah populasi tidak diketahui secara pasti sehingga untuk menghitung sampel minimum, teknik sampling yang digunakan adalah rumus Lemeshow. Perumusan Lemeshow yang digunakan adalah sebagai berikut:

$n=\frac{Z^{2} \times P(1-P)}{d^{2}}$

Keterangan:

$\mathrm{n}=$ Jumlah sampel

$Z=$ Skor $z$ pada kepercayaan $90 \%=1,64$

$\mathrm{P}=$ Maksimal estimasi $=0,5$

$\mathrm{d}=$ Alpha $(0,10)$ atau sampling error $=10 \%$

Maka hasil yang didapat adalah sebagai berikut:

$\mathrm{n}=\frac{1,64^{2} \times 0,5(1-0,5)}{0,1^{2}}$

$\mathrm{n}=\frac{2,6896 \times 0,5(1-0,5)}{0,01}$

$\mathrm{n}=\frac{0,6724}{0,01}$

$\mathrm{n}=67,24 \approx 68$

\section{Kriteria Penilaian Investasi}

Dimana :

$r=$ Tingkat bunga pengembalian

$\mathrm{N}=$ Tahun

Dengan ketentuan :

Jika NPV positif, maka investasi diterima, sedangkanjika NPV negatif, sebaiknya investasi ditolak.

3. Internal Rate Of Return (IRR)

Internal Rate Of Return (IRR) merupakan alat untuk mengukur tingkat pengembalian hasil intern. Adapun cara
Ada beberapa kriteria untuk menentukan apakah suatu usaha layak atau tidak dijalankan ditinjau dari aspek keuangan. Sedangkan metode penilaian yang akan digunakan adalah sebagai berikut (Kasmir dan Jakfar, 2012):

1. Payback Period (PP)

Metode Payback Period (PP) merupakan teknik penilaian terhadap jangka waktu (periode) pengembalian investasi suatu usaha atau proyek.

$$
\mathrm{PP} \quad=\quad n+\left(\frac{\mathrm{a}-\mathrm{b}}{\mathrm{c}-\mathrm{b}}\right) \cdot 12
$$

Dimana :

$\mathrm{n}=$ tahun terakhir dimana kas bersih belum bisa menutupi biaya investasi $a=$ jumlah investasi

$\mathrm{b}=$ jumlah kumulatif kas bersih pada tahun ke-n

$\mathrm{c}=$ jumlah kumulatif kas bersih pada tahun ke- $\mathrm{n}+1$

2. Net Present Value (NPV)

Net Present Value (NPV) atau nilai bersih sekarang merupakan perbandingan antara Present Value (PV) kas bersih (PV dari proses) dengan PV investasi (capital outlays/modal yang dikeluarkan) selama umur investasi. Rumus yang biasa digunakan dalam menghitung NPV adalah sebagai berikut (Kasmir dan Jakfar, 2012):

$$
\begin{aligned}
N P V=\frac{\text { Kas Bersih } 1}{(1+\mathrm{r})}+\frac{\text { Kas Bersih } 2}{(1+\mathrm{r})^{2}} \\
\\
\quad+\ldots \frac{\text { Kas Bersih N }}{(1+\mathrm{r})^{\mathrm{n}}}-\text { Investasi }
\end{aligned}
$$

yang digunakan untuk mencari IRR, dengan menggunakan rumus sebagai berikut:

\footnotetext{
$\mathrm{IRR}=$

Dimana:

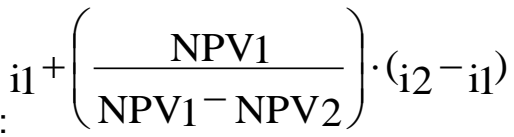

$\mathrm{i}_{1}=$ Tingkat bunga 1

$\mathrm{i}_{2}=$ Tingkat bunga 2

Jika perhitungan dengan cara trial and error, maka IRR dapat dicari dengan cara mencari NPV positif dan NPV negatif
} 
terlebih dahulu sampai diperoleh dengan menggunakan tingkat suku bunga tertentu.

Kesimpulan :

Jika IRR lebih besar (>) dari bunga pinjaman maka diterima.

Jika IRR lebih kecil (<) dari bunga pinjaman maka ditolak.

\section{Harga Pokok Produksi}

Untuk mencari harga pokok produksi berikut merupakan cara dan persamaan yang digunakan (Kasmir dan Jakfar, 2012):

Biaya bahan baku $\quad=R p . x x x$

Biaya tenaga kerja langsung $=R p \cdot x x x$

Biaya overhead pabrik $\quad=R p . x x x+$

HPP (Harga Pokok Produksi) $=$

\section{Metode Mark Up}

Mark up dapat ditentukan dari biaya produksi dan harga jualnya. Jika dari biaya produksi maka persentase mark up tersebut harus dikalikan dengan biaya produksi, kemudian ditambahkan pada biaya produksi sehingga menghasilkan harga mark up dan apabila ditentukan dari harga jualnya, lebih kompleks karena tidak dikalikan dengan biayanya, tetapi harga jual ditentukan dari biaya dibagi dengan satu dikurangi persentase mark up. Salah satu alasan menggunakan mark up adalah karena kurangnya kepastian mengenai biaya dari pada permintaan (Kasmir dan Jakfar, 2012).

Untuk menentukan harga jual dengan metode mark up digunakan persamaan sebagai berikut (Kasmir dan Jakfar, 2012):

Harga jual = biaya produksi + mark up

= biaya produksi $+(\%$ x biaya produksi $)$

\section{Metode Penelitian}

Data yang dibutuhkan dalam penelitian ini adalah kuesioner yang disebar untuk 68 responden yang memiliki anak dengan rentang usia 4-7 tahun. Tahapan yang dilakukan pada penelitian yaitu dengan melakukan pengolahan pada aspek pasar dan pemasaran, aspek teknis dan aspek finansial. Aspek pasar dan pemasaran dilakukan untuk menilai berapa persen respon dari orang tua anak usia dini setuju dengan produk puzzle huruf hijaiyah tersebut. Aspek teknis dilakukan untuk meindentifikasi bahan baku, alat yang digunakan, proses produksi, BOM (Bill of Material) dan Assembly Chart produk puzzle huruf hijaiyah. Aspek finansial untuk melihat kelayakan investasi produk puzzle huruf hijaiyah.

\section{Hasil dan Pembahasan}

\section{Aspek pasar dan pemasaran}

Lampiran 1 menunjukkan rekapitulasi skor ideal terhadap kuesioner yang disebar untuk 68 responden orang tua yang memiliki anak rentang usia 4 hingga 7 tahun terhadap penyataan pernyataan yang diberikan

Dari lampiran 1 diperoleh tingkat persetujuan terhadap 15 pernyataan yang diberikan berada di atas $90,29 \%$ yang berarti pernyataan-pernyataan yang diberikan kepada setiap responden, responden menyetujuinya.

\section{Forecasting}

Berikut data penjualan produk puzzle di Pekanbaru didapat dari 2 toko supplier dan 1 toko online yang ada di Pekanbaru.

Tabel 3. Jumlah Pesanan Alat Permainan Edukatif berbentuk Puzzle di Pekanbaru

\begin{tabular}{|c|l|c|}
\hline No & \multicolumn{1}{|c|}{ Nama Usaha } & Banyaknya Pesanan / Bulan \\
\hline 1 & Jojo Toys & $60 \mathrm{pcs}$ \\
\hline 2 & Aulia Toys & $74 \mathrm{pcs}$ \\
\hline 3 & Sales Muda (Buka Lapak) & $62 \mathrm{pcs}$ \\
\hline
\end{tabular}

(Sumber: Pengumpulan Data, 2018) 
Tabel 4. Rekapan Data Jumlah Pesanan Alat Permainan Edukatif berbentuk Puzzle di Pekanbaru

\begin{tabular}{|c|c|c|c|}
\hline No & Bulan & Tahun & Penjualan puzzle \\
\hline 1 & Oktober & 2017 & 196 Pcs \\
\hline 2 & November & 2017 & 195 Pcs \\
\hline 3 & Desember & 2017 & 200 Pcs \\
\hline 4 & Januari & 2018 & 202 Pcs \\
\hline 5 & Februari & 2018 & 195 Pcs \\
\hline 6 & Maret & 2018 & 206 Pcs \\
\hline 7 & April & 2018 & 200 Pcs \\
\hline 8 & Mei & 2018 & 210 Pcs \\
\hline 9 & Juni & 2018 & 200 Pcs \\
\hline 10 & Juli & 2018 & 210 Pcs \\
\hline 11 & Agustus & 2018 & 205 Pcs \\
\hline
\end{tabular}

(Sumber: Pengumpulan Data, 2018)

Peramalan dilakukan menggunakan analisis tren untuk memproyeksikan penjualan pada masa yang akan datang berdasarkan data sebelumnya. Pengolahan Tabel 5. Lembar Kerja Analisis Trend Least Square

\begin{tabular}{|c|c|c|c|c|c|c|}
\hline No & Bulan & Tahun & Periode (X) & Penjualan (Y) & $\mathbf{X Y}$ & $\mathbf{X}^{2}$ \\
\hline 1 & Oktober & 2017 & -5 & 196 Pcs & -980 & 25 \\
\hline 2 & November & 2017 & -4 & 195 Pcs & -780 & 16 \\
\hline 3 & Desember & 2017 & -3 & 200 Pcs & -600 & 9 \\
\hline 4 & Januari & 2018 & -2 & 202 Pcs & -404 & 4 \\
\hline 5 & Februari & 2018 & -1 & 195 Pcs & -195 & 1 \\
\hline 6 & Maret & 2018 & 0 & 206 Pcs & 0 & 0 \\
\hline 7 & April & 2018 & 1 & 200 Pcs & 200 & 1 \\
\hline 8 & Mei & 2018 & 2 & 210 Pcs & 420 & 4 \\
\hline 9 & Juni & 2018 & 3 & 200 Pcs & 600 & 9 \\
\hline 10 & Juli & 2018 & 4 & 210 Pcs & 840 & 16 \\
\hline 11 & Agustus & 2018 & 5 & 205 Pcs & 1025 & 25 \\
\hline
\end{tabular}

(Sumber : Pengolahan Data, 2018)

Berdasarkan tabel tersebut dapat diketahui :

$$
\begin{aligned}
\mathrm{n} & =11 \\
\sum \mathrm{Y} & =2219 \\
\sum \mathrm{XY} & =126 \\
\sum \mathrm{X}^{2} & =110
\end{aligned}
$$

Dengan demikian, koefisien trend least square nya adalah sebagai berikut:

$$
\begin{aligned}
\mathrm{a} & =\frac{\sum \mathrm{Y}}{\mathrm{n}} \\
& =\frac{2219}{11} \\
& =201,73 \\
\mathrm{~b} & =\frac{\sum \mathrm{XY}}{\sum \mathrm{X}^{2}} \\
& =\frac{126}{110} \\
& =1,15
\end{aligned}
$$

Maka persamaan trend least square nya adalah sebagai berikut:

$Y=a+b X$

$Y=201,73+1,15 X$ forecasting ini dapat dilakukan dengan menggunakan metode peramalan yaitu Analisis Trend Least Square 


\section{Aspek teknis}

Bahan baku utama untuk produk Puzzle huruf hijaiyah ini ialah kayu balsa. Berikut beberapa bahan baku yang digunakan untuk proses produksi Puzzle huruf hijaiyah:

1. Kayu Balsa

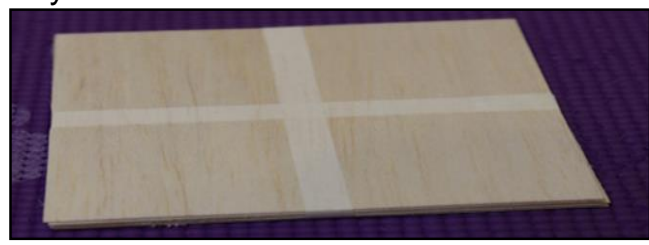

Gambar 2. Kayu Balsa

Dibanding pada jenis kayu lainnya, kayu balsa memiliki struktur yang halus dan lebih ringan, tetapi tetap memiliki bentuk yang kokoh. Kayu balsa biasa dipakai menjadi bahan baku utama pada permainan anak berbahan kayu. Sehingga pemilihan kayu balsa dirasa aman dan cocok untuk menjadi bahan baku utama proses produksi produk Puzzle huruf hijaiyah.

2. Cat Kayu Anti Toxic

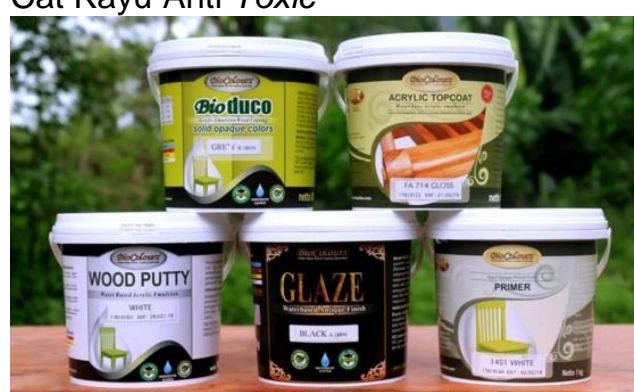

Gambar 3. Cat Kayu Biocolours

Cat kayu anti toxic dipilih karena tidak mengandung racun, ramah lingkungan dan aman bagi anak. Kandungan cat ini juga rendah timbal dan merkuri. Cat ini tidak mengeluarkan bau yang menyengat seperti cat minyak lainnya karena tidak terlalu banyak mengandung formalin. Inilah alasan mengapa cat kayu Biocolours tidak mengadung toxic berbahaya dan aman digunakan untuk proses produksi produk Puzzle huruf hijaiyah.

3. Engsel

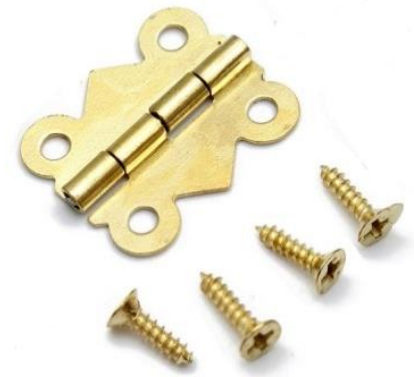

Gambar 4. Engsel Kupu-Kupu

Engsel yang dipilih untuk bahan baku proses produksi Puzzle huruf hijaiyah ialah engsel kupu-kupu. Engsel ini bentuknya tipis dan bahannya terbuat dari bahan kuningan.
Engsel ini biasanya dipakai untuk beban yang tidak terlalu berat, itulah mengapa engsel ini cocok untuk dipakai pada produk. Engsel ini berukuran 1,5 inch dan digunakan 2 buah engsel kupu-kupu untuk membuat satu produk permainan Puzzle huruf hijaiyah

4. Lem

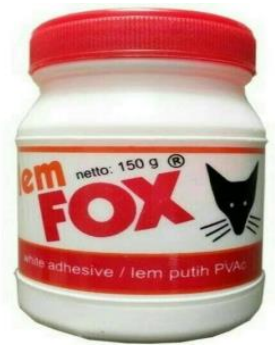

Gambar 5. Lem Putih PVAc

Lem digunakan untuk merekatkan dua sisi kayu. Lem yang digunakan untuk proses produksi produk Puzzle huruf hijaiyah ini ialah lem putih PVAc. Ketika menggunakan lem ini kita harus menunggu atau membiarkan lem mengering selama 10 menit sebelum kita merekatkan sisi-sisi permukaan kayu.

5. Pasak

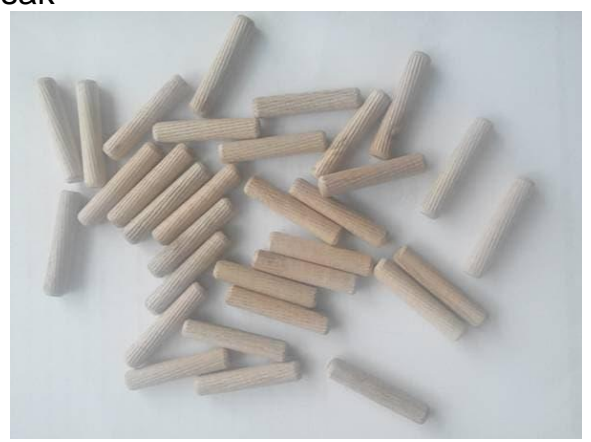

Gambar 6. Pasak Kayu

Jenis pasak yang digunakan dalam proses produksi produk puzzle huruf hijaiyah ialah pasak kayu. Pasak ini berfungsi untuk menghubungkan dua part antara alas kayu dan penyangga kayu yang sudah dilubangi terlebih dahulu. Pasak yang digunakan dalam proses pembuatan satu produk ialah 8 pcs pasak kayu.

6. Pengunci Papan
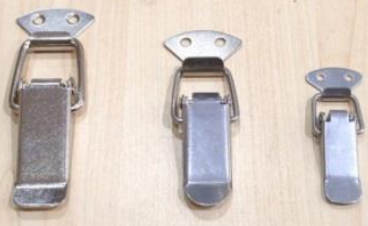

Gambar 7. Pengunci Papan

Pengunci papan digunakan untuk menutup dan mengunci part bagian papan atas dan papan bawah, sehingga saat anak selesai bermain, produk dapat disimpan dengan aman dan kepingan puzzle didalam kemasan tidak berserakan keluar. 
7. Pegangan (Handle) Papan

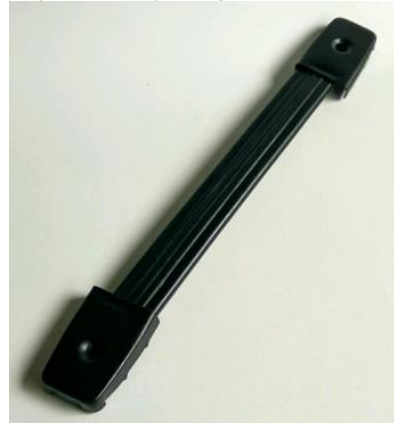

Gambar 8. Pegangan (Handle) Papan Handle merupakan pegangan, tangkai ataupun gagang yang dipasang pada produk. Handle tidak hanya berfungsi sebagai tarikan produk tetapi juga lebih mempunyai fungsi dan nilai tambah yang menonjolkan keserasian, keseimbangan, dan nilai estetik (keindahan) dari suatu produk puzzle huruf hijaiyah.

\section{Penentuan Alat yang Digunakan}

Berikut beberapa alat yang digunakan untuk proses produksi Puzzle huruf hijaiyah dapat dilihat di tabel 6 .

\section{Proses Produksi}

Berikut beberapa proses produksi yang dilakukan untuk menghasilkan produk puzzle huruf hijaiyah:

1. Pengukuran

Proses pertama dalam proses produksi puzzle huruf hijaiyah ialah dengan mengukur material kayu balsa sesuai ukuran yang dibutuhkan. Part-part yang diukur ialah kepingan puzzle, pegangan papan, penyangga pegangan, penyangga kunci, penyangga papan, papan belakang, papan puzzle. Proses pengukuran dilakukan dengan alat bantu meteran dan pensil.

2. Pemotongan

Setelah semua part diukur, maka langkah selanjutnya ialah memotong part tersebut sesuai dengan ukurannya masing-masing. Pemotongan dilakukan dengan mesin potong atau gergaji manual atau juga gergaji mesin. Setelah semua part dipotong, part dihaluskan menggunakan amplas agar permukaan bekas potongan yang kasar tidak melukai anak saat menggunakan produk.

3. Pengukiran

Langkah ketiga dalam proses produksi produk puzzle huruf hijaiyah ialah pengukiran. Pengukiran yaitu proses mengukir part papan puzzle dan kepingan puzzle. Pengukiran ini dilakukan dengan mesin CNC. Setelah part selesai diukir, selanjutnya part dibersihkan dengan kuas dan permukaan kasar bekas ukiran dihaluskan menggunakan amplas.
Tabel 7. Alat-alat yang digunakan untuk proses produksi produk puzzle huruf hijaiyah

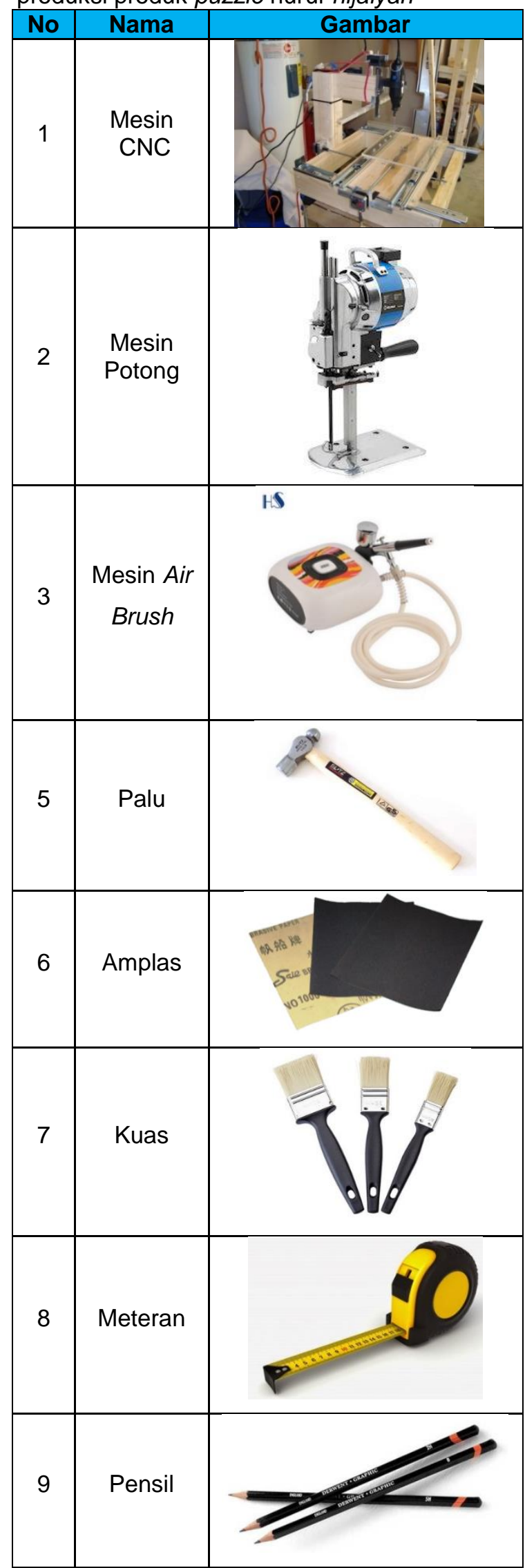

(Sumber: Pengolahan Data, 2018) 
4. Pengeboran

Pengeboran adalah suatu proses pengerjaan pemotongan menggunakan mata bor (twist drill) untuk menghasilkan lubang yang bulat pada material kayu. Lubang ini nantinya digunakan sebagai pemasangan pasak yang berguna untuk menyatukan antar dua part penyangga papan agar kokoh dan tidak saling lepas saat digunakan. Pengeboran ini dilakukan dengan mesin bor.

5. Perakitan

Selanjutnya yaitu proses perakiran. Proses perakitan ialah merakit atau menggabungkan part-part yang saling berhubungan. Adapun part-part tersebut dapat dilihat pada Gambar 10. assembly chart proses produksi produk puzzle huruf hijaiyah. Proses perakitan menggunakan alat bantu pasak, palu dan lem.

6. Pengecatan

Setelah semua part dirakit dan disatukan, maka langkah selanjutnya ialah melakukan pengecatan pada permukaan part yang telah selesai dirakit. Pengecatan ini dilakukan menggunakan mesin air brush.

7. Quality control

Langkah terakhir dalam proses produksi produk puzzle huruf hijaiyah ialah dengan melakukan quality control. Tujuan dari Quality control ialah untuk mengecek apakah terjadi defect atau kecacatan pada produk. Quality control dilakukan untuk menjamin kualitas produk yang baik sebelum produk sampai ke tangan konsumen.

\section{BOM (Bill Of Materials)}

BOM (Bill Of Materials) yang digunakan pada proses produksi produk puzzle huruf hijaiyah dapat dilihat dilampiran.

\section{Aspek finansial}

\section{Harga Pokok Produksi}

Adapun komponen biaya yang dikeluarkan dalam satu kali pembuatan produk adalah sebagai berikut:

Tabel 8. Biaya Bahan Baku

\begin{tabular}{|c|l|r|}
\hline No & \multicolumn{1}{|c|}{ Jenis Bahan } & \multicolumn{1}{c|}{ Total (Rp) } \\
\hline 1 & Kayu balsa & $52.500,00$ \\
\hline 2 & $\begin{array}{l}\text { Cat kayu anti } \\
\text { toxic }\end{array}$ & $20.000,00$ \\
\hline 3 & Engsel & $2.400,00$ \\
\hline 4 & Pasak & $2.000,00$ \\
\hline 5 & Lem & $1.000,00$ \\
\hline 6 & Pengunci papan & $8.000,00$ \\
\hline 7 & Pegangan papan & $13.500,00$ \\
\hline \multicolumn{2}{|c|}{ Total keseluruhan } & $99.400,00$ \\
\hline
\end{tabular}

(Sumber: Pengolahan Data, 2018)

\section{Harga Jual dengan Metode Mark Up}

Berikut hasil pengolahan menggunakan metode mark up:

Harga jual $=$ Rp. $99.400+(50 \% \times$ Rp. 99.400$)$

$$
\begin{aligned}
& =\text { Rp. } 99.400+(\text { Rp. } 49.700) \\
& =\text { Rp. } 149.100 \approx \text { Rp. } 150.000
\end{aligned}
$$

\section{Minimum Attractive Rate of Return (MARR)}

Berikut rumus MARR.

MARR $=\mathrm{i}+\alpha+$ ekspektasi laba

Dimana :

$\mathrm{i}=$ bunga deposito bank; $5 \%$ pada bulan November 2018 pertahunnya (Bank $\mathrm{BRI})$

$\alpha=$ high risk return (persen resiko pengembalian); $3 \%$ (karena produk bisa rusak apabila disimpan dalam jangka waktu yang lama)

MARR $=5 \%+3 \%+0 \%$

MARR $=8 \%$

Ekspektasi laba $=0 \%$

\section{Net Present Value (NPV)}

NPV =Total PV Kas Bersih - Total PV

Investasi

$N P V=R p 991.251 .456-R p 166.536 .000$

$\mathrm{NPV}=\mathrm{Rp} 824.715 .456$

\section{Internal Rate of Return (IRR)}

$$
\begin{aligned}
& \operatorname{IRR}=\mathrm{i}_{1}+\left(\frac{\mathrm{NPV}_{1}}{\mathrm{NPV}_{1}-\mathrm{NPV}_{2}}\right) \cdot\left(\mathrm{i}_{2}-\mathrm{i}_{1}\right) \\
& \operatorname{IRR}=0,08+ \\
& \left(\frac{824.715 .456}{824.715 .456-372.976 .488}\right) \cdot(0,4-0,08) \\
& \operatorname{IRR}=0,08+1,83 \times 0,32 \\
& \operatorname{IRR}=0,67=67 \% \\
& \operatorname{IRR}>\text { MARR }=67 \%>8 \%
\end{aligned}
$$

\section{Payback Periode (PP)}

$\mathrm{PP}=\frac{166.536 .000}{104.092 .000} \times 1$ tahun

$\mathrm{PP}=1,6$ tahun

Jadi, pengembalian modal pada investasi adalah selama 1 tahun 7 bulan 6 hari.

\section{Simpulan}

Dari hasil pengolahan data dan analisa terhadap data, maka diperoleh kesimpulan. Aspek pasar dan pemasaran produksi produk puzzle huruf hijaiyah, dapat dilihat dari pengolahan data kuesioner yang telah disebar diperoleh tingkat persetujuan terhadap 15 pernyataan yang diberikan berada di atas $90,29 \%$ yang berarti pernyataan-pernyataan yang diberikan kepada setiap responden, responden menyetujuinya.

Aspek teknis dan teknologi, produksi produk puzzle huruf hijaiyah akan diperhatikan penentuan bahan baku, alat yang digunakan dan proses produksi yang dilakukan. BOM (Bill 
of material) memberikan informasi lead time dari kayu balsa selama satu minggu, maka perusahaan harus melakukan perencanaan penjadwalan pemesanan untuk melakukan safety stock agar tidak terjadinya kekosongan bahan baku yang akan membuat terhambatnya proses produksi. AC (Assembly Chart) memberikan informasi part-part perakitan pada sub sub assembly yang telah diberikan.

Rencana kebutuhan investasi yang dibutuhkan untuk pembuatan usaha ini adalah Rp 166.536.000. NPV sebesar Rp 824.715.456 dengan tingkat suku bunga $8 \%$ yang memiliki nilai positif maka usaha produk puzzle huruf hijaiyah ini layak dan menguntungkan jika dikembangkan. Tingkat IRR yang dicapai dalam periode 4 tahun adalah $67 \%$ dimana nilai tersebut lebih besar dari nilai MARR yang ditetapkan oleh pihak perusahaan yaitu $8 \%$. Payback Period yang didapat adalah 1 tahun 7 bulan 6 hari. Hal ini menunjukkan usaha ini layak untuk di kembangkan karena dalam waktu 1 tahun 7 bulan 6 hari telah dapat mengembalikan modal yang di investasikan.

\section{Daftar Pustaka}

Aditya, A, S, Bakar, A dan Fitria, L, "Analisis Kelayakan Usaha Lemari/Rak Simple and Easy Delivery di Kecamatan Cikarang", No. 04, Vol. 01, Jurnal Online Institut Teknologi Nasional, Jurusan Teknik Industri, Itenas, Bandung, 2014

Fahmi, I., "Studi Kelayakan Bisnis dan Keputusan Investasi". Edisi Pertama, Mitra Wacana Media, Jakarta, 2014.

Handayani, D, A. "Feasibility Analysis of Business "Amalia Boutique" PT. Warna Warni Amalia As Muslimah Fashion In Shouth Jakarta". No. 01, Vol. 07, Jurnal Riset Manajemen Sains Indonesia, 2016. Kasmir dan Jakfar., "Studi Kelayakan Bisnis". Edisi Kedua, Kencana Media Group, Jakarta, 2012.

Osunbor, O, C. "A Guide to Electrical Power Substation Feasibility Study". Issue 12, Vol. 09, Department of Electrical Engineering, Nnamdi Azikiwe University Awka, Anambra State, Nigeria. 2017.

Lampiran 1

\begin{tabular}{|c|c|c|c|}
\hline \multicolumn{2}{|c|}{ Variabel Produk } & Total Skor & Tingkat Persetujuan \\
\hline No & \multicolumn{3}{|l|}{ Pernyataan } \\
\hline 1 & Produk permainan sesuai usia anak & 312 & $91,76 \%$ \\
\hline 2 & Warna kemasan produk menarik perhatian anak & 321 & $94,41 \%$ \\
\hline 3 & $\begin{array}{l}\text { Jenis bahan produk yang digunakan berkualitas dan aman } \\
\text { untuk anak }\end{array}$ & 310 & $91,17 \%$ \\
\hline 4 & $\begin{array}{l}\text { Ukiran produk sesuai untuk anak dan mudah dibawa } \\
\text { kemana-mana }\end{array}$ & 309 & $90,88 \%$ \\
\hline 5 & $\begin{array}{l}\text { Produk bisa menjadi media untuk anak agar dapat } \\
\text { bekerjasama dan berkomunikasi } \\
\text { sepermainannya }\end{array}$ & 313 & $92,05 \%$ \\
\hline 6 & $\begin{array}{l}\text { Produk dapat mengembangkan kemampuan fisik, nalar dan } \\
\text { kreativitas anak }\end{array}$ & 317 & $93,23 \%$ \\
\hline \multicolumn{4}{|c|}{ Variabel Harga } \\
\hline No & \multicolumn{3}{|l|}{ Pernyataan } \\
\hline 1 & $\begin{array}{l}\text { Harga produk tidak terlalu mahal dan sesuai dengan jenis } \\
\text { produk }\end{array}$ & 309 & $90,88 \%$ \\
\hline 2 & $\begin{array}{l}\text { Harga yang dipasarkan sesuai dengan jenis dan karakter } \\
\text { produk }\end{array}$ & 307 & $90,29 \%$ \\
\hline 3 & $\begin{array}{l}\text { Harga yang diberikan kepada konsumen dapat menjamin } \\
\text { kualitas produk }\end{array}$ & 308 & $90,58 \%$ \\
\hline 4 & Memberikan diskon dari harga normal & 310 & $91,17 \%$ \\
\hline \multicolumn{4}{|c|}{ Variabel Keputusan Konsumen } \\
\hline No & \multicolumn{3}{|l|}{ Pernyataan } \\
\hline 1 & $\begin{array}{l}\text { Saya membeli produk karena menarik dan beredukasi untuk } \\
\text { anak }\end{array}$ & 323 & $95 \%$ \\
\hline 2 & $\begin{array}{l}\text { Saya membeli produk permainan puzzle karena dapat } \\
\text { mengurangi waktu bermain anak dengan gadget }\end{array}$ & 312 & $91,76 \%$ \\
\hline 3 & $\begin{array}{l}\text { Saya membeli produk karena permainan puzzle memberikan } \\
\text { edukasi bahasa arab untuk anak }\end{array}$ & 311 & $91,47 \%$ \\
\hline 4 & Harga mempengaruhi saya untuk membeli produk & 315 & $92,64 \%$ \\
\hline 5 & $\begin{array}{l}\text { Kemasan dan harga akan menjadi pertimbangan saya untuk } \\
\text { membeli atau tidaknya produk tersebut }\end{array}$ & 315 & $92,64 \%$ \\
\hline
\end{tabular}




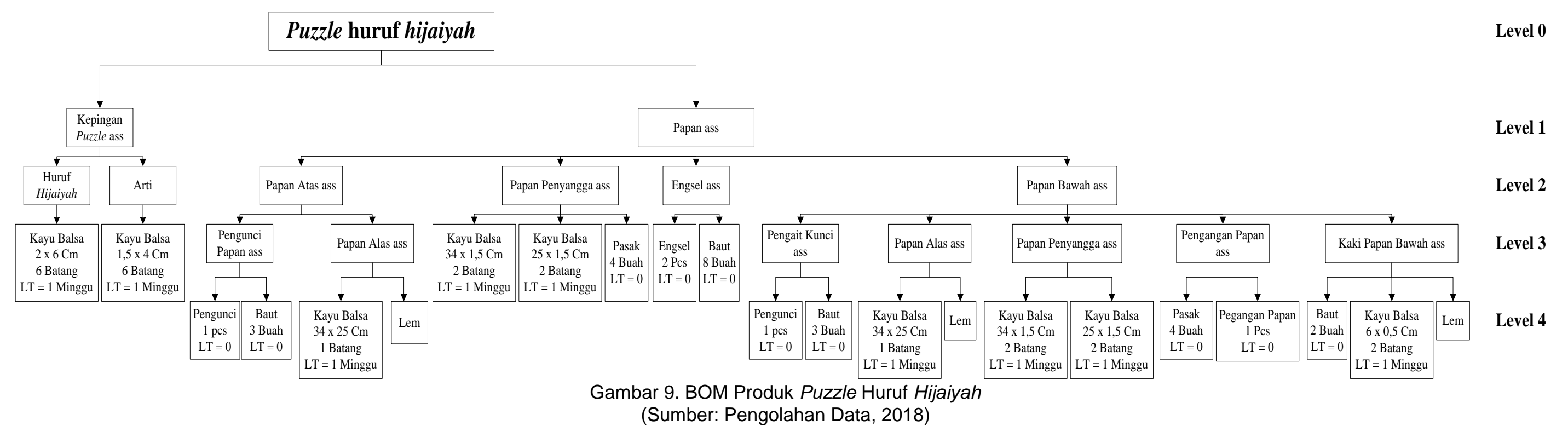




\section{Assembly Chart}

Berikut gambar Assembly Chart untuk proses produksi produk puzzle huruf hijaiyah:

ASSEMBLY CHART

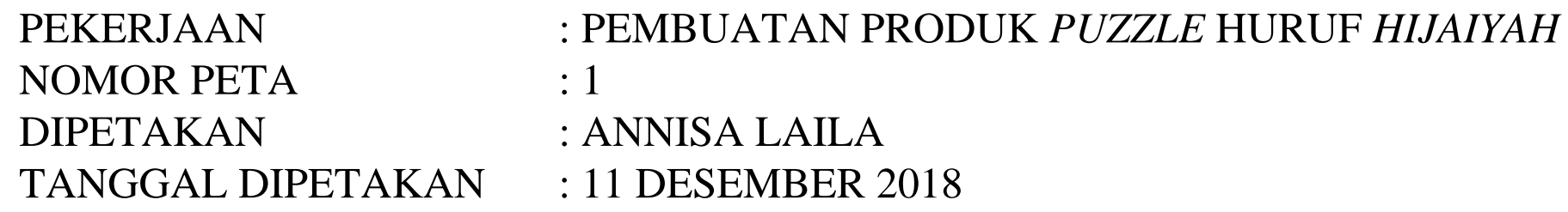

PEKERJAAN NOMOR PETA DIPETAKAN : PEMBUATAN PRODUK PUZZLE HURUF HIJAIYAH $: 1$ TANGGAL DIPETAKAN

: ANNISA LAILA

: 11 DESEMBER 2018
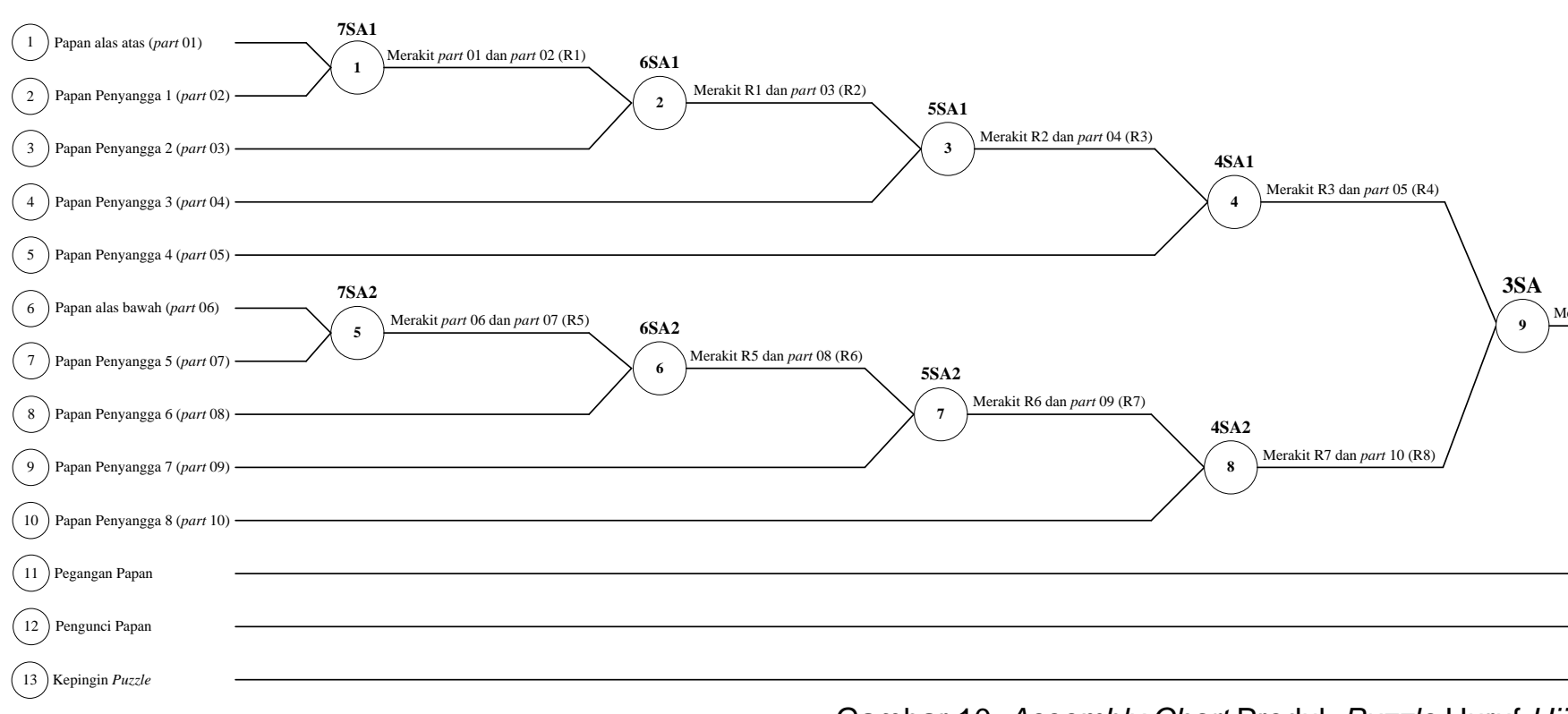

$7 \mathrm{SA2}$

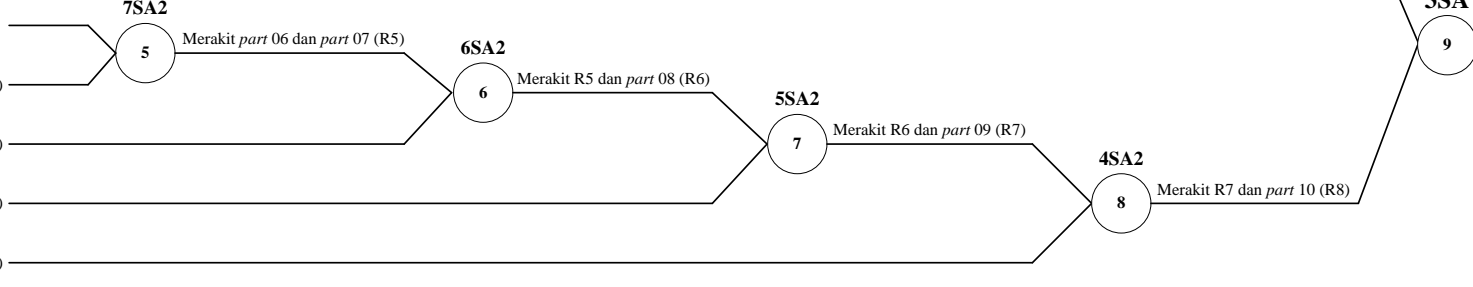

Gambar 10. Assembly Chart Produk Puzzle Huruf Hijaiyah

(Sumber: Pengolahan Data, 2018) 